\title{
Attractive papers and accurate English
}

\author{
Andreas F. Mavrogenis ${ }^{1}$ - Andrew Quaile ${ }^{2}$ Marius M. Scarlat ${ }^{3}$
}

Published online: 16 March 2016

(C) SICOT aisbl 2016

Medical writing has a long and distinguished history. It shows the latest considerations about the diagnosis, treatment, prevention, prognosis, practice management, surgical approaches or techniques and much more. Once the privilege of few clinical scholars in the field of orthopaedics, medical writing has recently become a must for career advancement. Writing a scientific paper that will get published is one of the most rewarding achievements in a medical career [1]. However, medical writing should include both medical knowledge and expertise in writing. Moreover, writing medical literature has its own special considerations, with rules and standards; it should be easy to understand, precise and should not confuse the readers. A physician who wants to share his research with colleagues communicates that responsible experience. Yet, some write, while others do not. Those who write gain intellectual stimulation, generate discussion, advance their discipline, enhance their reputation, and/or earn income. Those who do not write claim not having enough time. They blame the assistant or secretarial support, having no mentor or enough knowledge to express. Lack of time for research and writing is an important reason, especially for physicians in private practice. In contrast, lack of secretarial help, collegial support, and research access are not as valid now because of the computers and Internet [2-4].

Preparation of a manuscript crowns the mountain of hard work that preceded it, starting from defining a rationale (re-

Marius M. Scarlat

mscarlat@gmail.com

1 ATTIKON University Hospital, Athens, Greece

2 Spineworks, Hampshire Clinic, Basingstoke, Hampshire, UK

3 Clinique St. Michel, 83100 Toulon, France search question), writing a protocol, submitting it to the Institutional Review Board (IRB) for approval, recruitment of patients and data analysis. Yet, publication is not guaranteed; reporting a large series does not merit publication unless important and/or novel information is provided. Moreover, publication depends not only on the methodology used and quality of data analysis, but also on how the paper is written [1]. An article submitted to our Journal is first seen by the Publishing Assistant who will check if the submission fits the Journal standards, if the references are formatted according to the Instructions for the authors and if the word count is within reasonable limits. The papers that qualify are sent to the Editor and therefore a cover letter is recommended; this may be the first item that the Editor reads about the study. It should be personal and explain why the study was performed. It should be addressed with the manuscript and include the date of submission and the title. The Editor rapidly reviews the article to see if it falls within the Journal's scope and if it is prepared according to the Instructions for Authors; articles that are outside the Journal's scope, report an unimportant topic, include outdated information, provide conclusions that are inconsistent with the data, and those that are carelessly prepared are immediately rejected and returned to the authors. If the paper matches the Editor's criteria, it is sent to Reviewers for peer review. The Reviewers agree or decline to review and are encouraged to write a thoughtful review that is honest and free of bias, confident, and polite, suggesting a decision to the Editor. The assigned Reviewers are generally chosen for personal experience, many are senior academicians and researchers, yet all are volunteers. In our Journal policy we try to involve new and young reviewers matching them with the more experienced ones. Their role is to advise the Editor and eventually to help the authors to improve their production [3-5]. 
In the review process, the fundamental questions to be answered are:

(1) Is the rationale/hypothesis, original, and interesting?

(2) Does and how the study merits publication?

(3) Are the methods valid?

(4) Do data and literature support the conclusions?

If those requirements are met, a section by section review follows. Any written advice and critic is transmitted to the authors who have 1 month to change or improve the paper. If needed the authors may ask for a longer delay by sending a direct e-mail to the Publisher or to the Editor.

A manuscript should be adequately illustrated; our readership enjoys all illustrations and surgeons like graphic content, schemes, drawings and pictures. The illustrations should express important features of the methods and results. They should be limited to the essential for understanding the manuscript and should be in high quality for viewing according to the Instructions for Authors. Most important, illustrations should have adequate and meaningful legends. Clinical photographs should be accurate and not allow the patient identification. Tables are welcome to summarize complex collections of data. A table that summarizes the results of the most important published related studies is often useful to allow the readers to make comparisons easily [3-5]. In the era of the Internet, attractive scientific papers are still short, clear and well illustrated. It is only the support that changes, paper or electronic formats are acceptable for sharing information from surgery, clinical cases, series, scales and measurements, patient status and results. We appreciate papers that discuss quality of life after surgery as our ultimate goal is to offer a better life to our patients [6]. As Editors we have the privilege to publish papers that we enjoy reading. We assume that an enjoyable article will help colleagues to learn and the old saying "a picture is worth a thousand words" perfectly applies to a surgical publication. We also learned from social media and Altmetrics that papers that include educational videos are highly appreciated [7-10].

English language grammar and syntax is usually edited by the office and by the Associate Editor in charge of this delicate mission. In our Journal the choice was historically defined by Franck Horan and Tony Hall to use British English as standard because originally the SICOT was created in Europe and our Publisher is European. As the United Kingdom is (still) a part of Europe the choice for British English is still the rule... This final editing may not be sufficient in some cases and substantial work would be required mainly in cases where the author's English proficiency is low. In that case, we recommend manuscript editing by a professional or a native speaker prior to submission. A clear and concise language will help editors and reviewers concentrate on the scientific content of the paper and thus smoothen the peer review process. The expression should be formal and conform to the standard rules of spelling and grammar; contractions and redundancy should be avoided, and punctuation should be used correctly. Percentages should be rounded to whole numbers; decimals make sense only if they contain important information. Tables and illustrations should be referred parenthetically and statements in which a table or illustration subject or object of a sentence should be avoided. When reviewing a resubmission, all comments should be addressed in the text. Furthermore, all comments should be addressed in a "Cover letter to Editor" with point-by-point answers to Editor's and Reviewers' comments and remarks; this makes easier to re-review and suggests careful revision writing of the paper. If the authors disagree with an Editor's or Reviewer's comment, they should clearly state why. The Editor makes the final decision based on the recommendations of the Reviewers and his own personal review $[3,4,11]$.

As the official journal of SICOT we publish articles from many countries around the world including articles from authors in developing countries. The quality is not always the same but we presume that the authors improve with each written paper and our aim is to support the spirit of the SICOT where every surgeon could join to learn and improve. Every year more than 3000 submissions are received at the Journal and more than 1000 are immediately rejected as being out of the scope of the Journal or written in an inappropriate format. The high number of submissions creates a challenging problem of balance between the interests of our members, the authors, our readers and the maintenance of a high Impact Factor for the journal [12]. Each year we publish 12 issues of on average 200 pages that are distributed to our subscribers and libraries all over the world. The volume of received manuscripts continues to increase in a plethoric way and this pressured us to reduce the acceptance ratio from $23.0 \%$ in 2013 to less than $11 \%$ currently and we will have to continue this reduction in the future along with quality concerns that are more and more severe [11].

Speed of publication is one of our major concerns. The time from receipt of an article to the acceptance/rejection is between three and six weeks on average depending on the type of manuscript; and from acceptance to publication ONLINE FIRST about one month; the appearance in the printed journal issue takes between three and six months and we are keen to avoid increasing the waiting time. This creates pressure on the Editors but also on reviewers and writers. Over the years, the names of all the reviewers have been published and acknowledged at the February Issue (No2) of the Journal. It is a moral rule that writers accept and acknowledge the hard role of the reviewers who analyze and help to improve the quality of a paper and to be respectful to the reviewers; most reviewers are trying hard to help authors to improve their manuscript, and to recognize weaknesses in their study and manuscript presentation.

After acceptance, the article is on the way to proof reading and print; authors should go through the galley proofs of their 
manuscript, addressed succinctly the questions raised by the typesetter, and return the manuscript promptly. Failure to do so, delays publication and impedes the work of the editorial office since the journal probably has already reserved space in an upcoming issue.

For writing success, this paper aimed to provide helpful recommendations for scientific, elegant, well illustrated and meaningful writing. We wish you to enjoy reading "International Orthopaedics" and publishing with us.

\section{References}

1. Mauffrey C, Scarlat MM, Pećina M (2014) Setting standards for medical writing in orthopaedics. Int Orthop 38(1):1-5. doi:10.1007/ s00264-013-2189-6

2. Taylor RB (2005) The clinician's guide to medical writing. Springer Science \& Business Media. ISBN: 978-0-387-22249-3 (Print) 9780-387-27024-1 (Online)

3. Brand RA (2008) Writing for clinical orthopaedics and related research. Clin Orthop Relat Res 466(1):239-247. doi:10.1007/ s11999-007-0038-x

4. Brand RA (2012) Reviewing for clinical orthopaedics and related research. Clin Orthop Relat Res 470(9):2622-2625. doi:10.1007/ s11999-012-2447-8
5. International Orthopaedics. Instructions for authors (2015) Available at: http://www.springer.com/medicine/orthopedics/ journal/264. Accessed $15 \mathrm{Feb} 2016$

6. Kolk A, Wolterbeek N, Auw Yang KG, Zijl JA, Wessel RN (2016) Predictors of disease-specific quality of life after arthroscopic rotator cuff repair. Int Orthop 40(2):323-329. doi:10.1007/s00264-0152996-Z

7. Faldini C, Nanni M, Traina F, Fabbri D, Borghi R, Giannini S (2016) Surgical treatment of hallux valgus associated with flexible flatfoot during growing age. Int Orthop. doi:10.1007/s00264-0153019-9

8. Faldini C, De Fine M, Di Martino A, Fabbri D, Borghi R, Pungetti C, Traina F (2016) Anterior minimally invasive subcapital osteotomy without hip dislocation for slipped capital femoral epiphysis. Int Orthop. doi:10.1007/s00264-0153015-0

9. Hernigou P (2016) The Vienna and German heritage of orthopaedics from the first half of the twentieth century: Adolf Lorenz, Lorenz Böhler, Friedrich Pauwels, Gerhard Küntscher Int Orthop. doi:10.1007/s00264-015-3101-3

10. Scarlat MM, Mavrogenis AF, Pećina M, Niculescu M (2015) Impact and alternative metrics for medical publishing: our experience with International Orthopaedics. Int Orthop 39(8):1459-1464. doi:10.1007/s00264-015-2766-y

11. Pećina M (2015) International orthopaedics today. Int Orthop 39(3): 381-382. doi:10.1007/s00264-014-2638-x

12. King LS (1991) Why not say it clearly: a guide to expository writing. Little, Brown and Company, Boston, ISBN-13: 9780316493536 